\title{
Celovito obvladovanje kakovosti pri izvajanju nalog lokalne skupnosti: primer predšolske vzgoje
}

UDK: 005.336.3:373.2

Jože Benčina

Univerza v Ljubljani, Fakulteta za upravo

joze.bencina@fu.uni-lj.si

Srečko Devjak

Univerza v Ljubljani, Fakulteta za upravo

srecko.devjak@fu.uni-li.si

\section{IZVLEČEK}

$\checkmark$ prispevku predstavljamo izziv vzpostavitve trdnega upravljavskega okvira izvajanja nalog lokalne skupnosti. Na osnovi predpostavke, da je vzpostavitev celovitega obvladovanja kakovosti za napredek tega področja ključnega pomena, smo se pri odkrivanju priložnosti za izbolišanje naslonili na skupni ocenjevalni okvir CAF. Raziskava obravnava področje vzgoje in izobraževanja. Osrednje raziskovalno vprašanje je, kako odgovorni v lokalnih skupnostih za predšolsko vzgojo poznajo in razumejo odgovornost občinskih uprav za uspešno izvajanje nalog iz njihovih pristojnosti. Raziskava je v metodološkem smislu pokazala, da je z uporabo ustrezno oblikovanih vprašalnikov upoštevajoč model CAF v lokalnih skupnostih mogoče odkriti ključne priložnosti za izboljšanje upravljanja $z$ nalogami v pristojnosti občine. Rezultati raziskave na področju predšolske vzgoje kažejo, da občinske uprave dobro obvladujejo finančno področje in se pri načrtovanju osredotočajo predvsem na investicijski (prostorski) vidik. Kot ključna priložnost za izbolišanje se je izkazalo obvladovanje kakovosti. Odkrite priložnosti za izboljšanje izkazujejo potrebo po nadalinii teoretični obdelavi problema, ki bo osnova za praktične usmeritve $v$ obliki dobrih praks in prenos znanja v prakso.

Ključne besede: lokalna skupnost, upravljanje, izvajanje nalog,
predšolska vzgoja, CAF

JEL: D63, D73

Benčina, J. \& Devjak, S. (2011). Celovito obvladovanje kakovosti

pri izvajanju nalog lokalne skupnosti: primer predšolske vzgoje.

Uprava, IX(2), 37-57. 


\section{Uvod}

Ključnega pomena za kakovost bivanja občanov v občini je kakovost storitev, ki jih izvaja občina za zadovoljevanje potreb svojih prebivalcev. Z zakonom o lokalni samoupravi (ZLS, 2009, čl. 49) ${ }^{1}$ so določene izvirne naloge, za katere so občine neposredno pristojne. Prav tako je s tem zakonom opredeljeno, da občina izvaja tudi tiste naloge, ki jih na občino s posebnimi zakoni prenese država, pri tem pa mora država za te storitve zagotavljati ustrezna dodatna sredstva. Pri tem mora upoštevali predvsem dve določili iz Zakona o lokalni samoupravi: (1) "Občina mora biti sposobna zadovoljevati potrebe in interese svojih prebivalcev in izpolnjevati druge naloge v skladu z zakonom. « (ZLS, 2009, čl. 13) in (2) "Občinska uprava opravlja upravne, strokovne, pospeševalne in razvojne naloge ter naloge $v$ zvezi z zagotavljanjem javnih služb iz občinske pristojnosti.« (ZLS, 2009, čl. 49). Za smotrno ${ }^{2}$ izvajanje izvirnih nalog v smislu obstoječe zakonodaje je $v$ celoti odgovorna lokalna skupnost.

Osrednje vprašanje $v$ zvezi s tem je, kako občine izvajajo izvirne naloge z vidika upravljanja (uspešnosti), menedžmenta (učinkovitosti) in kakovosti storitev. V prispevku obravnavamo problematiko upravljanja, menedžmenta in zagotavljanja kakovosti izvajanja izvirnih nalog občine z dveh osnovnih vidikov: a) splošnega, ki skrbi za zadovoljevanje potreb občanov po določenih vrstah storitev in b) strokovnega, ki pomeni strokovni razvoj storitev in kakovosti storitev.

Najboliše rezultate dosegajo tako profitne kot neprofitne organizacije le z ustreznim pristopom $\mathrm{v}$ okviru paradigme celovitega obvladovanja kakovosti (TQM) in upoštevanjem osnovnih načel analize primerjalnega preskušanja. Model odličnosti EFQM ${ }^{3}$ (Kovač \& Kern-Pipan, 2008) je primeren okvir za uveljavljanje celovitega obvladovanja kakovosti (BouLlusar et al., 2009). Kot orodje za uveljavljanje modela odličnosti EFQM $\checkmark$ javnem sektorju se vse bolj uveljavlja samoocenjevalni pristop CAF Skupni ocenjevalni okvir (Kovač, 2002). Primeri celovitega pristopa $k$ obvladovanju kakovosti kažejo, da je treba pri uvajanju pristopa upoštevati tako organizacijski vidik kot vidik uveljavljanja uporabe orodii za zagotavlianja kakovosti, kot sta na primer CAF in sistem uravnoteženih

$1 \mathrm{~V}$ nadaljevanju bomo za Zakon o lokalni samoupravi uporabljali v besedilu kratico ZLS. 2 Smotrno - pojem zajema: gospodarnost, učinkovitost, uspešnost, etiko, kakovost ... 3 EFQM - European Foundation for Quality Management. Model odličnosti EFQM model, ki je osnova za podeljevanje nagrad evropske fondacije za menedžment kakovosti. 
kazalnikov (Gent, 2006). Model EFQM oziroma CAF je zastavlien vzročno posledično, predpostavlja, da izboljševanje stanja dejavnikov izboljšuje rezultate. Preverjanje teoretičnih izhodišč $z$ empiričnim modeliranjem za podatke za poljske lokalne skupnosti kaže, da izhodiščni dejavnik modela - vodenje vpliva na strategijo in načrtovanje, oba skupaj pa na zaposlene, ki prenašajo vpliv na procese, kamor dajejo svoj prispevek tudi viri in partnerstva. Procesi pa nato vplivajo na rezultate za stranke (občane), ki se prelivajo v ključne rezultate delovanja (Bugdol in Jarzebinski, 2010). Pregled virov kaže, da je področje deležno velike pozornosti praktikov in je uveljavljanje celovitega obvladovanja kakovosti v povezavi z modelom CAF v lokalnih skupnostih dokaj razširjena praksa, čemur počasi sledi tudi rast znanstvenoraziskovalnih prispevkov. Mani pa je študii, ki bi obravnavale problematiko delitve vlog pri zagotavljanju kakovosti podobnih storitev $v$ lokalnih skupnostih, zato $v$ rezultatih dosedanjih raziskav ne najdemo konkretnih primernih rešitev za obravnavani problem. Zato bomo v prispevku prikazali, kako lahko primerno prilagojen pristop CAF uporabimo kot orodje za zagotavljanje kakovosti izvajanja tistih nalog lokalnih skupnosti, katerih operativno izvajanje je predano javnim ali zasebnim organizacijam.

Navedeno problematiko predstavljamo na primeru predšolske vzgoje. Občina je zadolžena za predšolsko vzgojo na svojem področju (ZLS, 2009, čl. 32). V splošnem to pomeni, da je pristojna za ustanavljanje vrtcev, ki delujejo po predpisanem programu (kurikulu za vrtce, 1999) ali za podelitev koncesije za izvajanje predpisanih programov ali pa ( $v$ splošnem) sofinancira izvajanje predšolske vzgoje po drugih, alternativnih programih. V upravljanje dejavnosti predšolske vzgoje so vključeni: občina (župan, organi občine, strokovni delavci občinske uprave), sveti zavodov, upravljanje vrtca, idr. Do sedaj uveljavljeni pristopi obvladovanja kakovosti s samoocenjevanjem za lokalno skupnost niso povsem primerno uporablieni, saj mora lokalna skupnost po eni strani delovati $v$ smeri odličnosti, po drugi strani pa mora z nadzorovanjem in ukrepanjem zagotavljati kakovost delovanja vrtcev, ki jih tudi financira in za njih zagotavlja investicijska vlaganja. $V$ praksi se tako pojavi problem, da vloge $v$ sistemu celovitega zagotavljanja kakovosti $v$ predšolski vzgoji niso jasno razmejene. Lokalne skupnosti zato ne prevzamejo vseh nalog in odgovornosti, ki bi jih morale prevzemati. Občine praviloma skrbijo le za materialne pogoje delovanja vrtcev, za druge funkcije razvoja predšolske vzgoje in za smotrnost delovanja predšolske vzgoje pa ne čutijo posebne 
odgovornosti. S tem ni izpolnjen osnovni pogoj za uspešno celovito obvladovanje razvoja kakovosti predšolske vzgoje v slovenskih občinah.

$\checkmark$ prispevku se bomo zato osredotočili na obravnavo problema celovitega obvladovanja kakovosti na relaciji lokalna skupnost - vrtec: izvajalec predšolske vzgoje v občini. Na osnovi ocenjevalne sheme CAF smo $\vee$ okviru projekta "Reggio Emilia" ${ }^{4}$ pripravili ustrezen vprašalnik. Z njim smo iskali odgovore tudi na naslednii dve raziskovalni vprašanji, ki sta predmet obravnave tega prispevka:

- kako odgovorni v lokalni skupnosti za področje predšolske vzgoje dojemajo odgovornost in pristojnost za zagotavljanje kakovosti predšolske vzgoje za vsa merila modela CAF in

- kako lokalne skupnosti (odgovorne osebe za predšolsko vzgojo) ocenjujejo dejavnike in rezultate na področju predšolske vzgoje.

\section{Obvladovanje kakovosti storitev v lokalni skupnosti}

Predšolska vzgoja je proračunsko pomembna naloga $v$ slovenskih lokalni skupnosti, zato ni vseeno, kako se načrtuje in kako se izvaja. Predšolsko vzgojo $v$ Sloveniji izvajajo predvsem $v$ javnih vrtcih, $v$ manjši meri pa tudi $\vee$ zasebnih vrtcih. $\vee$ vrtce se vključujejo otroci od enega leta starosti do vstopa $v$ šolo. Predšolska vzgoja ni obvezna. Zagotavljanje predšolske vzgoje je ena izmed temeljnih nalog občine (Vlaj, 2001), vrtce ustanavliajo in financirajo občine.

Predšolsko vzgojo v slovenskih vrtcih urejajo naslednji zakoni: Zakon o organizaciji in financiranju vzgoje in izobraževanja (1996), Zakon o vrtcih (1996) in Zakon o lokalni samoupravi (2009). Zakon o organizaciii in financiranju vzgoje in izobraževanja ureja pogoje za opravljanje ter določa način upravljanja in financiranja na vseh področjih vzgoje in izobraževanja. Zakon o vrtcih pa ureja predšolsko vzgojo, ki poteka v javnih in zasebnih vrtcih (naloge vrtcev, cilji in načela, vrsta možnih programov v vrtcih, financiranje, pogoji za izobrazbo strokovnih delavcev, delovna obveznost vzgojitelja in pomočnika vzgojitelja, zbiranje in varstvo osebnih podatkov $v$ vrtcu ipd.).

4 Projekt "Profesionalno usposabljanje strokovnih delavcev za izvajanje elementov posebnih pedagoških načel koncepta Reggio Emilia na področju predšolske vzgoje" (2008-2013) je projekt, ki ga financirata Evropski socialni sklad in Ministrstvo za šolstvo in šport in se izvaja na Pedagoški fakulteti Univerze v Ljubljani. 
Ustanavljanje in financiranje predšolske vzgoje je ena od pomembnih nalog občine. Odgovornost pristojnih služb je, da poskrbijo za ustrezno in kakovostno izvajanje te dejavnosti, ki je sicer pravno-formalno in normativno določena (ZLS, 2009; Zakon o vrtcih, 2008), vendar je uresničitev določenih standardov na področju predšolske vzgoje odvisna od različnih dejavnikov, interesov in potreb posameznih podsistemov (starši, politične stranke, strokovni delavci vrtca, strokovni delavci občine itd.). Kakovosti izvajanja neke dejavnosti $v$ občini, $v$ našem primeru predšolske vzgoje, se marsikdaj zaradi različnih dejavnikov posveča premalo načrtne in dosledne pozornosti.

Državna uprava in občine $v$ Sloveniji $v$ zadnjem času $v$ vedno večjem obsegu uvajajo za področje ocenjevanja kakovosti dela evropski model CAF - Skupni ocenjevalni okvir za organizacije v javnem sektorju (CAF Common Assessment Framework. Povzet je po evropskem modelu odličnosti EFQM in pomeni orodje za izboljšanje organizacije oz. javne uprave s pomočjo samoocenitve. Ta model je tudi del dokumenta Politika kakovosti slovenske javne uprave, ki ga je decembra 2003 sprejela vlada Republike Slovenije. Model CAF je okvir, ki je enostaven za uporabo in primeren za samoocenjevanje organizacij v javnem sektorju.

CAF kot model za uvajanje kakovosti in odličnosti je javni upravi najboli prilagojeni pripomoček za izboljšanje uspešnosti delovanja. Ob sprejetih načelih delovanja, določitvi vizije, poslanstva in vrednot, ki jih uprava želi razvijati in izboljševati, CAF omogoča zasledovanje ciljev, merjenje rezultatov in doseganja ciljev. $S$ tem lahko organizacija realno spremlja in ocenjuje lastni razvoj kakovosti in odličnosti. Bistvo tega modela je predvsem $v$ tem, da temelji na vključevanju vseh zaposlenih, uporabnikov storitev in partnerjev. Odpira nove možnosti v razumevanju in reševanju problemov kakovosti ter ustvarja večjo angažiranost in dinamiko znotraj kolektiva, kar je seveda ključno pri uvajanju in dvigu ravni dela $v$ organizacijah javnega sektorja, predvsem $v$ njenem odnosu do uporabnikov njenih storitev.

Model CAF (CAF, 2009) temelji na merjenju dejavnikov kakovosti in rezultatov kakovosti. Merjenje dejavnikov kakovosti je po skupinah razvrščeno v pet skupin: (1) voditeljstvo; (2) strategija in načrtovanje; (3) ravnanje z ljudmi pri delu, (4) partnerstva in viri in (5) upravljanje procesov in obvladovanje sprememb. Merjenje rezultatov kakovosti je po skupinah razvrščeno v štiri skupine: (1) rezultati za odjemalce, (2) rezultati 
za zaposlene, (3) rezultati za družbo in (4) ključni rezultati uspešnosti delovanja.

Model CAF je ponujen kot orodje za pomoč organizacijam javnega sektoria po vsej Evropi pri uporabi tehnik upravljanja kakovosti za izbolišanje uspešnosti delovanja. Štirje glavni nameni modela CAF so:

1. Zajeti vse posebnosti različnih organizacij v javnem sektorju.

2. Služiti kot orodje uslužbencem $v$ javnem sektorju, ki želijo izboljšati uspešnost delovanja svoje organizacije.

3. Delovati kot "most" med različnimi modeli upravljanja kakovosti.

4. Omogočati lažjo primerjavo z drugimi organizacijami (angl. benchmarking) v javnem sektorju.

Omenjeni model je mogoče uporabljati v vseh delih javnega sektorja, ki jih sestavljajo javne organizacije na nacionalni, regionalni ali lokalni ravni. Prav tako se lahko uporablja v najrazličnejših okoliščinah, npr. kot del sistematičnega programa prenove ali kot osnova za postavljanje ciljev pri prizadevanjih za izboljšanje javnih storitvenih organizacij. CAF omogoča in zagotavlia:

- ocenjevanje, ki temelii na dokazih,

- doseganje skladnosti usmeritve in soglasja glede tega, kaj je treba storiti za izbolišanje organizacije,

- ocenjevanje po postavljenih merilih, ki so širše sprejeta v Evropi,

- periodično samoocenjevanje za preverjanje napredka,

- povezavo med cilii in podpornimi strategijami ter procesi,

- osredotočenost dejavnosti izboliševanja na tista področja, kjer je najboli potrebno,

- napredovanje in izmenjavo dobre prakse med različnimi področji organizacije ter z drugimi organizacijami,

- ustvarjanje navdušenja med zaposlenimi z njihovim vključevanjem $\checkmark$ proces izboljševanja,

- priložnosti za prepoznavanje napredka in izjemnih dosežkov,

- vgrajevanje raznih pobud kakovosti v tekoče poslovanje.

Različni avtorii (Calvo-Mora et al., 2005; Castresana \& FernándezOrtiz, 2005) dokazujejo, da so modeli odličnosti, med njimi najboli 
razširjena $M B N Q A^{5}$ in $E F Q M^{6}$, zelo uporaben okvir za uveljavljanje celovitega obvladovanja kakovosti ((Bou-Llusar et al., 2009)). Model CAF je $v$ primerjavi z njima "preprost" model, ki je primeren zlasti za spoznavanje delovanja organizacije. Pričakuje se, da bo organizacija, ki namerava napredovati, izbrala enega od podrobnejših modelov (kot npr. modela Speyer ali EFQM). Prednost modela CAF je $v$ tem, da je z omenjenima modeloma združljiv in je tako lahko prvi korak za organizacijo, ki želi nadaljevati z upravljanjem lastne kakovosti.

\section{Metodologija}

Kot smo že omenili, standardni pristop CAF za obravnavo specifičnih okoliščin $v$ lokalni skupnosti ni povsem primeren, saj mora lokalna skupnost upravljati predšolsko vzgojo $v$ razmeriu $z$ izvajalci te naloge. Zato smo vprašalnik za ocenjevanje kakovosti delovanja predšolske vzgoje na osnovi modela CAF razširili tako, da anketiranci poleg dejavnikov in rezultatov za izvajalce predšolske vzgoje (posredno samoocenjevanje) ocenjujejo tudi lastno delovanje (neposredno samoocenjevanje). Vprašanj za neposredno samoocenjevanje nismo dodali le pri treh merilih odličnosti (dejavnik zaposleni in rezultati za zaposlene in družbo).

Izhajajoč iz raziskovalnih vprašani smo tako postavili naslednji hipotezi:

- odgovorni za predšolsko vzgojo v lokalnih skupnostih ne delujejo v smeri celovitega obvladovanja kakovosti,

- odgovorni za predšolsko vzgojo v lokalnih skupnostih ocenjujejo lastno delovanje bolje ali enako kot delovanje izvajalcev predšolske vzgoje.

Pri prvi hipotezi, da odgovorni za razvoj in delovanje predšolske vzgoje ne delujejo $v$ smeri celovitega obvladovanja kakovosti, smo pri preverjanju izhajali iz predpostavke, da bi morale lokalne skupnosti obvladovati ključna vzročna dejavnika zagotavljanja kakovosti (voditeljstvo, politiko in strategijo (Bugdol \& Jarzebinski, 2010)). Hipotezo smo preverili z obravnavo odstopanj $v$ rezultatih ankete in sicer $z$ :

5 Malcolm Baldrige National Quality Award

6 European Foundation for Quality Management 
- analizo ranžirne vrste aritmetičnih sredin rezultatov ankete; spremenljivke, katerih rezultati se uvrščajo v drugi decil, prinašajo sliko o priložnostih za izbolišanje (najslabše ocenjenih elementih meril odličnosti) in

- analizo manjkajočih vrednosti pri vprašanjih o rezultatih za odjemalce in zaposlene; odstopanja pri manjkajočih vrednostih, ki se nanašajo na ocenjevanje rezultatov zelo verjetno pomenijo, da respondenti ali ne vedo, da se ti rezultati merijo, ali pa teh rezultatov ne poznajo.

Drugo hipotezo, odgovorni za razvoj in delovanje predšolske vzgoje v lokalnih skupnostih ocenjujejo lastno delovanje bolje ali enako kot delovanje izvajalcev predšolske vzgoje, smo postavili z namenom, da bi predstavili pogled lokalnih skupnosti na delovanje izvajalcev predšolske vzgoje in njihovo lastno vlogo pri tem. Preverili smo jo s primerjavo ocen neposrednega samoocenjevanja z ocenami posrednega samoocenjevanja.

Vprašalnik obsega 84 vprašani v 13 sklopih (položaj vrtcev v lokalni skupnosti (8), 9 meril CAF (58), poznavanje pedagoškega koncepta vrtcev Reggio Emilia (1), ocena prioritet meril CAF (9) in splošni podatki (8)), pri večini med njimi smo uporabili 5-mestno Likertovo ocenjevalno lestvico.

Tabela 1: Porazdelitev vprašanj na neposredno in posredno ocenjevanje meril CAF

\begin{tabular}{|l|c|c|c|}
\hline \multirow{2}{*}{ Merila odličnosti } & \multicolumn{3}{|c|}{ Število vprašani za samoocenjevanje } \\
\cline { 2 - 4 } & neposredno & posredno & skupai \\
\hline Voditelistvo & 1 & 3 & 4 \\
\hline Politika in strategija & 4 & 2 & 6 \\
\hline Zaposleni & 0 & 5 & 5 \\
\hline Partnerstva in viri & 2 & 7 & 9 \\
\hline Procesi & 3 & 8 & 11 \\
\hline Rezultati - zaposleni & 0 & 5 & 5 \\
\hline Rezultati - odjemalci & 3 & 4 & 7 \\
\hline Rezultati - družba & 0 & 8 & 8 \\
\hline Ključni rezultati delovanja & 1 & 2 & 3 \\
\hline
\end{tabular}

Vir: Raziskava občine, 2010 
Porazdelitev vprašani neposrednega (14) in posrednega samoocenjevanja (44) je podana $v$ tabeli 1 . Kot smo že omenili, vprašani za neposredno oceno nismo namenili dejavniku zaposleni in rezultatom za zaposlene in družbo.

Vprašalnik je bil razposlan vsem slovenskim občinam v oktobru 2009 po pošti. Na izpolnjene vprašalnike smo počakali 3 mesece.

\section{Rezultati}

Raziskava obravnava slovenske občine z vidika upravljanja predšolske vzgoje. Občine so glede tega različno organizirane, število izvajalcev predšolske vzgoje je tudi različno. $V$ raziskavi teh razlik ne upoštevamo. Populacija so odgovorne osebe za predšolsko vzgojo $v$ slovenskih občinah. Odzivnost je bila nizka: 20,5\% (43 vrnjenih vprašalnikov od 210 razdeljenih). Očitno bi bilo treba vložiti nekaj dodatnega truda $v$ motiviranje občinskih strokovnih služb, da bi bile bolj zainteresirane za sodelovanje $v$ takih raziskavah.

Morebitno pristranskost vzorca smo preverili s primerjavo frekvenčnih porazdelitev glede na število prebivalcev $v$ občinah za populacijo in vzorec (tabela 2).

\section{Tabela 2: Primerjava frekvenčnih porazdelitev populacije in vzorca}

\begin{tabular}{|r|r|r|r|r|r|}
\hline \multicolumn{1}{|c|}{ Število prebivalcev } & \multicolumn{2}{|c|}{ Populacija } & \multicolumn{2}{|c|}{ Vzorec } \\
\hline nad & \multicolumn{1}{c|}{ do } & $\mathrm{fi}$ & \multicolumn{1}{c|}{$\mathrm{fi}^{\circ}$} & $\mathrm{fi}$ & \multicolumn{1}{c|}{$\mathrm{fi}^{\circ}$} \\
\hline & 3000 & 57 & $27,1 \%$ & 7 & $16 \%$ \\
\hline 3000 & 5000 & 53 & $25,2 \%$ & 8 & $19 \%$ \\
\hline 5000 & 10000 & 47 & $22,4 \%$ & 12 & $28 \%$ \\
\hline 10000 & 20000 & 36 & $17,1 \%$ & 9 & $21 \%$ \\
\hline 20000 & 40000 & 12 & $5,7 \%$ & 5 & $12 \%$ \\
\hline 40000 & 300000 & 5 & $2,4 \%$ & 2 & $5 \%$ \\
\hline
\end{tabular}

Vir: Raziskava občine, 2010

Primerjava med relativnimi frekvencami kaže, da je $v$ vzorcu delež večjih občin nekoliko večji kot $v$ osnovni populaciji. Problematika upravljanja predšolske vzgoje je $\vee$ večjih občinah prav gotovo bolj kompleksna, zato je vzorec za obravnavo pojava prav gotovo primeren, $s$ tem da bi bilo treba $\vee$ nadaljnjih raziskavah preveriti morebitne razlike med manjšimi in večjimi občinami. 
Pregled respondentov po statističnih regijah kaže, da je regionalna zastopanost občin nekoliko neuravnotežena, največ občin, ki so izpolnile ankete, je iz goriške in osrednjeslovenske regije.

Pri obravnavi hipotez smo upoštevali prva dva sklopa vprašani (položaj vrtcev v lokalni skupnosti (8), 9 meril CAF (58)).

Prvo hipotezo, ki se glasi:

- odgovorni za predšolsko vzgojo v lokalnih skupnostih ne delujejo v smeri celovitega obvladovanja kakovosti,

smo preverili z analizo ranžirne vrste aritmetičnih sredin rezultatov ankete. Pri nekaterih vprašanjih, ki tvorijo pomemben del obvladovanja kakovosti, je bil delež manjkajočih odgovorov precej velik, zato smo v okviru razmisleka o hipotezi pripravili še analizo manjkajočih vrednosti.

Iz ranžirne vrste aritmetičnih sredin vseh obravnavanih spremenljivk smo izbrali tiste, katerih aritmetične sredine so manjše ali enake 2. decilu $(3,41)$. Pri tem smo upoštevali tudi vse spremenljivke, pri katerih enovzorčni t-test na vrednost 2 . decila pokaže, da jih ne moremo razlikovati od vrednosti 2. decila. Na ta način smo opredelili skupino 12 najnižje ocenjenih spremenljivk (tabela 3).

Prvi dve vprašanji prihajata iz sklopa ocenjevanja sodelovanja lokalne skupnosti z izvajalci predšolske vzgoje. Izračunani vrednosti sta med osmimi vprašanji s tega področja daleč najnižji. Respondenti ocenjujejo druge elemente sodelovanja na področju financiranja in splošno stanje predšolske vzgoje $\mathrm{z}$ bistveno višjimi ocenami od ocene lastne angažiranosti pri nadzoru kakovosti in učinkovitosti izvajanja predšolske vzgoje.

Med vrednostmi ocen za politiko in strategijo odstopa ocena uresničevanja strategije. Respondenti bistveno bolje ocenjujejo stanje glede opredelitve poslanstva, vizije in strategije, kar pomeni, da se zavedajo težavnega uresničevanja politike in strategije. Med nižje ocene se je pri merilu politika in strategija uvrstila še ocena načrtovanja in merjenja uspešnosti in učinkovitosti v vrtcih.

Med najnižje ocenjene spremenljivke se je od devetih spremenljivk merila partnerstva uvrstilo kar šest. Pri rezultatih za družbo je najslabše ocenjeno vprašanje, ki preverja enega od elementov koncepta predšolske vzgoje Reggio Emilia, in sicer odgovornost izvajalcev za obveščanje in za prenos znanja $\vee$ širšo javnost. 
Tabela 3: Pregled spremenliivk $z$ aritmetično sredino manjšo ali enako 2. decilu $(3,41)$

\begin{tabular}{|c|c|c|}
\hline Vprašanje & $\begin{array}{l}\text { Aritmetična } \\
\text { sredina }\end{array}$ & Merilo CAF \\
\hline Pogostost spremljanja kakovosti dela v vrtcu & 3,38 & voditeljstvo \\
\hline Spremljanje učinkovitost dela v vrtcu & 3,28 & voditeljstvo \\
\hline $\begin{array}{l}\text { Vodstva vrtcev si prizadevajo za uvajanje modelov in } \\
\text { standardov kakovosti kot npr. CAF, ISO. }\end{array}$ & 3,44 & voditeljstvo \\
\hline $\begin{array}{l}\text { Občina ima zapisano razvojno strategijo o predšolski } \\
\text { vzgoji, ki jo organi občine tudi uresničujejo. }\end{array}$ & 2,98 & $\begin{array}{l}\text { politika in } \\
\text { strategija }\end{array}$ \\
\hline $\begin{array}{l}\text { V vrtcih redno oblikujejo cilje za merjenje uspešnosti in } \\
\text { učinkovitosti izvajanja predšolske vzgoje in redno } \\
\text { analizirajo njihovo doseganje. }\end{array}$ & 3,49 & $\begin{array}{l}\text { politika in } \\
\text { strategija }\end{array}$ \\
\hline $\begin{array}{l}\text { Ocena skupnosti o kakovosti pretoka informacii, } \\
\text { spoznanj med raziskovalnimi institucijami, ki se } \\
\text { ukvarjajo s predšolsko vzgojo - npr. s fakulteto in vrtci. }\end{array}$ & 3,18 & $\begin{array}{l}\text { partnerstva } \\
\text { in viri }\end{array}$ \\
\hline $\begin{array}{l}\text { Mnenje lokalne skupnosti o kakovosti pretoka } \\
\text { informacii, spoznani med Zavodom za šolstvo in } \\
\text { vrtcem. }\end{array}$ & 3,36 & $\begin{array}{l}\text { partnerstva } \\
\text { in viri }\end{array}$ \\
\hline $\begin{array}{l}\text { Mnenje lokalne skupnosti o kakovosti pretoka } \\
\text { informacii, spoznani med Centrom za socialno delo, } \\
\text { vrtcem in lokalno skupnostjo. }\end{array}$ & 3,33 & $\begin{array}{l}\text { partnerstva } \\
\text { in viri }\end{array}$ \\
\hline $\begin{array}{l}\text { Vrtci spodbujajo starše in druge krajane (posameznike) } \\
\text { k sodelovanju pri izvajanju predšolske vzgoje in drugih } \\
\text { aktivnosti, pomembnih za dvig kakovosti v vrtcih } \\
\text { (mnenjske raziskave, krožki kakovosti, ankete, ipd.). }\end{array}$ & 3,67 & $\begin{array}{l}\text { partnerstva } \\
\text { in viri }\end{array}$ \\
\hline $\begin{array}{l}\text { Vrtci javnost redno obveščajo o pogojih in rezultatih } \\
\text { predšolske vzgoje primerjalno na sorodne } \\
\text { organizacije. }\end{array}$ & 3,38 & $\begin{array}{l}\text { partnerstva } \\
\text { in viri }\end{array}$ \\
\hline $\begin{array}{l}\text { Vrtci skrbijo za fizično dostopnost do stavb in prostorov } \\
\text { (parkirišča, invalidi, javna prevozna sredstva, ipd.). }\end{array}$ & 3,64 & $\begin{array}{l}\text { partnerstva } \\
\text { in viri }\end{array}$ \\
\hline $\begin{array}{l}\text { Vrtec aktivno seznanja širšo javnost v lokalni skupnosti } \\
\text { z novejšimi spoznanji vzgoje predšolskih otrok. }\end{array}$ & 3,14 & $\begin{array}{l}\text { rezultati - } \\
\text { družba }\end{array}$ \\
\hline
\end{tabular}

Vir: Raziskava občine, 2010

Analiza spremenliivk z najnižjimi vrednostmi kaže, da so priložnosti za izboljšanje predvsem $v$ treh dejavnikih, $v$ voditelistvu, politiki in strategiji in partnerstvih. Upoštevaje izsledke modeliranja vzročno posledičnih povezav $\checkmark$ modelu CAF (Bugdol \& Jarzebinski, 2010), ki izpostavlja kot ključna dejavnika prav voditelistvo in politiko in strategijo, lahko predpostavimo, 
Jože Benčina, Srečko Devjak

Celovito obvladovanje kakovosti pri izvajanju nalog lokalne

skupnosti: primer predšolske vzgoje

da bi lahko z izboljšanjem obeh vzročnih dejavnikov bistveno vplivali na izbolišanje rezultatov dejavnosti predšolske vzgoje.

Z analizo manjkajočih vrednosti smo preverili še spremenliivke, pri katerih smo zaznali več ko $20 \%$ delež manjkajočih odgovorov (tabela 4).

Tabela 4: Pregled spremenljivk z odstopajočim deležem manjkajočih vrednosti

\begin{tabular}{|c|c|c|c|c|}
\hline \multirow{2}{*}{ Vprašanje } & \multicolumn{2}{|c|}{$\begin{array}{l}\text { Manjkajoči } \\
\text { odgovori }\end{array}$} & \multirow{2}{*}{$\begin{array}{l}\text { Aritmetična } \\
\text { sredina }\end{array}$} & \multirow{2}{*}{$\begin{array}{l}\text { Merilo } \\
\text { CAF }\end{array}$} \\
\hline & število & delež & & \\
\hline $\begin{array}{l}\text { Vrtci imajo razdelane svoje razvoine } \\
\text { strategije. }\end{array}$ & 22 & $51,2 \%$ & 3,62 & $\begin{array}{l}\text { politika in } \\
\text { strategija }\end{array}$ \\
\hline $\begin{array}{l}\text { V vrtcih redno izvajajo ankete o } \\
\text { zadovoljstvu zaposlenih. }\end{array}$ & 12 & $27,9 \%$ & 3,00 & zaposleni \\
\hline $\begin{array}{l}\text { V vrtcih redno izvajajo ankete o } \\
\text { zadovoljstvu staršev s predšolsko vzgojo. }\end{array}$ & 9 & $20,9 \%$ & 2,35 & $\begin{array}{l}\text { rezultati - } \\
\text { odjemalci }\end{array}$ \\
\hline $\begin{array}{l}\text { Doseženi rezultati anket o zadovoljstvu } \\
\text { staršev so skladni s pričakovanii staršev. }\end{array}$ & 20 & $46,5 \%$ & 3,70 & $\begin{array}{l}\text { rezultati - } \\
\text { odjemalci }\end{array}$ \\
\hline $\begin{array}{l}\text { Doseženi rezultati anket o zadovoljstvu } \\
\text { staršev so skladni s politiko in strategijo } \\
\text { predšolske vzgoje }\end{array}$ & 20 & $46,5 \%$ & 3,78 & $\begin{array}{l}\text { rezultati - } \\
\text { odjemalci }\end{array}$ \\
\hline $\begin{array}{l}\text { Doseženi rezultati anket o zadovoljstvu } \\
\text { staršev kažejo, da se napake in nesreče } \\
\text { v vrtcih pojavljajo izjemoma. }\end{array}$ & 21 & $48,8 \%$ & 4,23 & $\begin{array}{l}\text { rezultati - } \\
\text { odjemalci }\end{array}$ \\
\hline $\begin{array}{l}\text { Doseženi rezultati anket o zadovoljstvu } \\
\text { staršev, ki jih izvaja občina, so skladni s } \\
\text { pričakovanii staršev. }\end{array}$ & 31 & $72,1 \%$ & 3,33 & $\begin{array}{l}\text { rezultati - } \\
\text { odjemalci }\end{array}$ \\
\hline $\begin{array}{l}\text { Doseženi rezultati anket o zadovoljstvu } \\
\text { staršev, ki jih izvaja občina so skladni } \\
\text { politiko in strategijo predšolske vzgoje v } \\
\text { občini. }\end{array}$ & 31 & $72,1 \%$ & 3,58 & $\begin{array}{l}\text { rezultati - } \\
\text { odjemalci }\end{array}$ \\
\hline $\begin{array}{l}\text { Rezultati ankete o zadovoljstvu } \\
\text { zaposlenih so nadpovprečni. }\end{array}$ & 21 & $48,8 \%$ & 3,14 & $\begin{array}{l}\text { rezultati - } \\
\text { zaposleni }\end{array}$ \\
\hline
\end{tabular}

Vir: Raziskava občine, 2010

Pri prvem vprašanju med navedenimi je šlo za napako v vprašalniku, saj so v tabeli za ocenjevanje manjkale vrednosti za obkroževanje, zato so mnogi respondenti ta odgovor spregledali.

Vse druge spremenljivke $\vee$ tabeli 4 , razen ene, ki se nanaša na rezultate za zaposlene, se nanašajo na rezultate za odjemalce. Pri pripravi vprašalnika nismo bili pozorni na možnost, da bi lahko bil osip odgovorov 
tako velik, zato ni bil povsem prilagojen preverjanju dejanskega razloga za neodgovor. Kljub temu pa lahko sklepamo, da je vzrok za številne manjkajoče vrednosti neizvajanje meritev ali nepoznavanje rezultatov meritev za rezultate za odjemalce. Iz danih dejstev lahko sklepamo, da odgovorni $v$ občinskih upravah za predšolsko vzgojo rezultatov za odjemalce ne obvladujejo.

Vsebinski razmislek torej kaže, da so največje priložnosti za izboljšanje povezane s ključnima dejavnikoma modela CAF, voditeljstvom in politiko in strategijo, ki sta tudi ključna vzvoda za doseganje dobrih rezultatov. Manjkajoči odgovori med vprašanji o izvajanju in rezultatih preverjanja zadovoljstva odjemalcev kažejo, da odgovorni za predšolsko vzgojo v občinah ne obvladujejo rezultatov delovanja vrtcev. Zbrana dejstva odkrivajo bistvene priložnosti za izboljšanje na področju upravljanje z dejavnostjo predšolske vzgoje pri dejavnikih voditeljstvo, politika in strategija, partnerstva in viri ter pri rezultatih za odjemalce.

Drugo hipotezo, ki se glasi

- odgovorni za predšolsko vzgojo v lokalnih skupnostih ocenjujejo lastno delovanje (neposredna ocena delovanja) bolje ali enako kot delovanje izvajalcev predšolske vzgoje (posredna ocena delovanja),

smo preverili s primerjavo ocen neposrednega samoocenjevanja $z$ ocenami posrednega samoocenjevanja. Hipoteza bo potrjena, če bo pri vseh primerjavah po elementih modela CAF (dejavnikih in rezultatih) med pari spremenliivk obeh kategorii veljalo, da so aritmetične sredine vrednosti spremenljivk, ki predstavljajo neposredno ocenjevanje, večje ali enake aritmetični sredini spremenljivk, ki predstavljajo posredno ocenjevanje.

Svoje delovanje so respondenti ocenili z odgovori na sklop vprašanj o sodelovanju lokalne skupnosti z vrtci in na izbrana vprašanja $v$ sklopih vprašani za merila CAF. Vprašanja iz sklopa o sodelovanju lokalne skupnosti z vrtci, ki so samoocena delovanja lokalne skupnosti v zvezi s finančno in strokovno podporo, z upoštevanjem predlogov staršev in izvajalcev predšolske vzgoje, ter $z$ zagotavljanjem kakovosti in učinkovitosti delovanja, smo smiselno razvrstili v ustrezna merila CAF. V tabeli 5 so prikazane vrednosti aritmetičnih sredin za neposredne in posredne samoocene po posameznih merilih CAF. Preverjanje hipoteze smo izvedli s preverjanjem statistične značilnosti razlik med aritmetičnimi 
Celovito obvladovanje kakovosti pri izvajanju nalog lokalne skupnosti: primer predšolske vzgoje

sredinami posameznih spremenliivk iz obeh razredov (neposredna samoocena in posredna samoocena) po elementih modela CAF.

Tabela 5: Pregled rezultatov neposrednega in posrednega samoocenjevanja

\begin{tabular}{|l|c|c|c|c|}
\hline \multirow{2}{*}{ Merilo CAF } & \multicolumn{2}{|c|}{ Neposredna samoocena } & \multicolumn{2}{c|}{ Posredna samoocena } \\
\cline { 2 - 5 } & $\begin{array}{c}\text { ševilo } \\
\text { spremenlijk }\end{array}$ & $\begin{array}{c}\text { aritmetična } \\
\text { sredina }\end{array}$ & $\begin{array}{c}\text { število } \\
\text { spremenljivk }\end{array}$ & $\begin{array}{c}\text { aritmetična } \\
\text { sredina }\end{array}$ \\
\hline Voditelistvo & 2 & 4,36 & 3 & 4,17 \\
\hline Politika in strategija & 4 & 3,67 & 2 & 3,49 \\
\hline Zaposleni & 0 & & 5 & 3,87 \\
\hline Partnerstva & 4 & 3,88 & 4 & 3,47 \\
\hline Viri & 2 & 4,47 & 3 & 3,88 \\
\hline Procesi a (da/ne) & 3 & 7,36 & 2 & 1,40 \\
\hline Procesi b (1-5) & 2 & 3,33 & 6 & 4,04 \\
\hline Rezultati - zaposleni & 0 & & 5 & 3,49 \\
\hline Rezultati - odjiemalci (izvajanje & 7 & 3,30 & 7 & 2,36 \\
\hline anket) & 2 & 3,46 & 2 & 3,71 \\
\hline Rezultati - odjemalci (dosežki) & 0 & & 8 & 4,03 \\
\hline Rezultati - družba & 2 & 4,24 & 2 & 4,12 \\
\hline Ključni rezultati delovanja & & & & \\
\hline
\end{tabular}

Vir: Raziskava občine, 2010

Med merili, kjer so respondenti podali neposredno in posredno oceno ( $v$ tabeli 5 so zapisani $v$ poševnem slogu), je točkovna ocena aritmetične sredine neposredne ocene (ocene lastnega dela) pri štirih merilih (voditeljstvo, politika in strategija, partnerstva in viri in ključni rezultati delovanja) večja od posredne ocene (ocene izvajalcev predšolske vzgoje), pri dveh merilih (procesi in rezultati odjemalci (dosežki) pa enaka. To izhodišče pomeni, da lahko pričakujemo, da postavliene hipoteze, da bodo vse primerjave spremenljivk neposrednega in posrednega ocenjevanja v okviru elementov modela CAF pokazale, da so neposredne ocene povsod večje ali enak posrednim, ne bo potrjena. Rezultate primeriani predstavljamo po elementih CAF, pri vsakem se tudi opredelimo do veljavnosti hipoteze.

Pri dejavniku voditeljstvo so vse točkovne ocene neposrednega ocenjevanja višje od točkovnih ocen posrednega ocenjevanja, pri čemer med šestimi pari samo pri enem razlika, preverjena s parnim t-testom, ni statistično značilna. Tako lahko hipotezo, da so ocene neposrednega 
ocenjevanja višje ali enake ocenam posrednega ocenjevanja za dejavnik voditeljstvo potrdimo.

Pri spremenljivkah, ki se nanašajo na politiko in strategijo, smo zaradi visokega deleža manjkajočih vrednosti iz obravnave izločili spremenljivko "Vrtci imajo razdelane svoje razvojne strategije", tako da nam je za primerjavo ostala le ena spremenljivka, ki se nanaša na delovanje vrtcev. Vzorčna ocena za aritmetično sredino neposredne samoocene je nižja od posredne le pri enem paru (nizka ocena trditve "Občina ima zapisano razvojno strategijo o predšolski vzgoji, ki jo organi občine tudi uresničujejo"), vendar ta razlika ni statistično značilna (rezultat parnega †testa $p=0,080)$. Hipotezo za dejavnik partnerstvo in viri lahko tako potrdimo (pri preostalih treh parih je neposredna ocena višja, pri enem tudi statistično značilna), s pripombo, da se odgovorni za predšolsko vzgojo $v$ občinah problematike uveljavljanja strategij ogibajo in so dokaj kritični do rezultatov svojega truda na tem področju.

Primerjavo v okviru spremenljivke partnerstva in viri smo razdelili na partnerstva in vire posebej. Partnerstvo obsega po štiri spremenljivke neposrednega in posrednega ocenjevanja. Med šestnajst primerjanimi pari je pri dveh parih točkovna ocena neposredne ocene manjša od posredne, vendar razlika ni statistično značilna. Med preostalimi pari z večjo vzorčno vrednostjo neposredne ocene je razlika kar pri desetih parih statistično značilna, pri štirih pa ne. Hipotezo za partnerstva $v$ dejavniku partnerstva in viri zato lahko potrdimo. Pri virih analiza obsega 6 parov spremenljivk. Vzorčne vrednosti neposrednega ocenjevanja so pri vseh parih višje od vzorčnih ocen posrednega ocenjevanja. Preverjanje $s$ pomočjo parnega t-testa razlik ne potrdi le pri enem paru. Torej lahko hipotezo potrdimo nad celotnim dejavnikom partnerstvo in viri $\mathrm{s}$ pripombo, da so razlike znatne, saj so pri večini parnih preverjani razlike potriene kot statistično značilne.

Pri ocenjevanju procesov sta bila uporabljena dva sklopa spremenljivk, 5 spremenljivk $\mathrm{z}$ binomialno ocenjevalno lestvico in 8 spremenljivk s petmestno ocenjevalno lestvico. Pri sklopu spremenljivk z binomialno lestvico sta aritmetični sredini neposrednih in posrednih ocen skoraj enaki, vendar se kar pri dveh parih pojavijo statistično značilne razlike med aritmetičnimi sredinami $v$ prid posrednim ocenam. S tem je hipoteza nad dejavnikom procesi zavrnjena že pri prvem delu obravnavanih spremenljivk. Primerjava aritmetičnih sredin preostalih ocen 
dejavnika procesi kaže, da so tudi tu vzorčne vrednosti neposrednih ocen dejavnosti nižje od posrednih ocen. Trditev obvelja tudi po preverjanju s parnim t-testom, saj so višje posredne ocene pri vseh parih tudi statistično značilne. Nad dejavnikom procesi hipotezo zavrnemo, praktično lahko nad tem dejavnikom trdimo, da so vse neposredne ocene manjše od (ali enake) od posrednih ocen.

Ocenjevanje rezultatov za odjemalce smo obravnavali z dvema sklopoma spremenljivk. Prvi primerjalni par je bila ocena, kako redno izvajajo ankete o zadovoljstvu staršev občine in vrtci posebej. Rezultat $s$ statistično značilnostjo ( $p=0,000$ ) kaže, da odgovorni $v$ občinskih upravah menijo, da občine bolj redno izvajajo meritve zadovoljstva strank kot vrtci. Primerjave ocen rezultatov kažejo, da so ocene anket občin slabše od ocen anket vrtcev, vendar zaradi velikega deleža manjkajočih vrednosti tega rezultata ne moremo uporabiti. Tako je smiselno, da zaradi premajhnega vzorca $(n=11)$ rezultate za odjemalce iz naše hipoteze izključimo.

Pri ključnih rezultatih delovanja smo primerjali po dve spremenljivki neposrednega in posrednega ocenjevanja. Pri dveh parih spremenljivk je točkovna ocena aritmetične sredine neposredne ocene večja od posredne, pri dveh pa je ravno obratno. Razlike so statistično značilne le pri razlikah $\vee$ korist neposredne ocene, zato lahko za ključne rezultate delovanje postavlieno hipotezo potrdimo.

Očitno je, da ničelne hipoteze, da lokalne skupnosti ocenjujejo lastno dejavnost slabše kot dejavnost izvajalcev predšolske vzgoje, pri vsaj eni spremenljivki ne moremo zavrniti. Pregled rezultatov preverjanja hipoteze po posameznih elementih modela CAF pa kaže, da lahko ničelno hipotezo, da lokalne skupnosti ocenjujejo lastno dejavnost slabše kot dejavnost izvajalcev predšolske vzgoje, zavrnemo pri dejavnikih voditeljstvo, politika in strategija, partnerstvo in viri in ključni rezultati delovanja. S tem smo za navedene dejavnike in ključne rezultate delovanja potrdili alternativno hipotezo, da so aritmetične sredine neposrednih ocen pri vseh primerjanih parih spremenljivk večje ali enake aritmetičnim sredinam posrednih ocen. Pri dejavniku procesi in rezultatih za odjemalce pa ničelne hipoteze ne moremo zavrniti, saj se pri obeh pojavi vsaj en par spremenljivk, kjer je aritmetična sredina neposredne ocene statistično značilno manjša od primerjane posredne ocene. 


\section{Razprava}

Odgovore na zastavljeni raziskovalni vprašanji:

- kako odgovorni v lokalni skupnosti za področje predšolske vzgoje dojemajo odgovornost in pristojnost za zagotavljanje kakovosti predšolske vzgoje za vsa merila modela CAF in

- kako lokalne skupnosti (odgovorne osebe za predšolsko vzgojo) ocenjujejo dejavnike in rezultate na področju predšolske vzgoje,

smo iskali s pomočjo dveh hipotez:

- odgovorni za predšolsko vzgojo v lokalnih skupnostih ne delujejo v smeri celovitega obvladovanja kakovosti in

- odgovorni za predšolsko vzgojo v lokalnih skupnostih ocenjujejo lastno delovanje bolje ali enako kot delovanje izvajalcev predšolske vzgoje.

Majhen vzorec in velik delež manjkajočih odgovorov pri nekaterih vprašanjih nas pri posploševanju rezultatov nekoliko omejujeta. Ker pa je bila raziskava usmerjena $v$ spoznavanje problemskega področja, lahko sprejmemo rezultate kot dobro izhodišče za načrtovane prihodnjih raziskav.

Iz rezultatov raziskave lahko ugotovimo, da imajo $v$ lokalnih skupnostih pri upravljanju pri izvajanju nalog številne priložnosti za izboljšanje:

- odgovorni v lokalnih skupnostih se ne zavedajo svoje ključne vloge pri uveljavljanju celovitega obvladovanja kakovosti pri izvajanju nalog iz niihove pristojnosti,

- s svojim prispevkom in stanjem na področju izvajanja nalog $v$ nịhovi pristojnosti so relativno zadovolini,

- pri ocenjevanju dejavnosti in rezultatov so nekoliko pristranski, lastni prispevek ocenjujejo bolje kot prispevek izvajalcev dejavnosti.

Prej navedena dejstva, za katera predvidevamo, da niso omejena samo na področje, ki smo ga obravnavali, smo ilustrirali na primeru predšolske vzgoje, kjer lahko iz rezultatov raziskave ugotovimo, da občinske uprave le delno spremljajo delovanje izvajalcev predšolske vzgoje in da nimajo izhodišč in koncepta, ki bi jih približali k celovitemu obvladovanju kakovosti. Ključne priložnosti za izboljšanje so: 
- nadzor kakovosti in učinkovitosti,

- uveljavljanje strategije,

- partnerstvo in viri in

- rezultati za odjemalce.

Manjkajoči odgovori pri vprašanjih, ki so se nanašala na rezultate za odjemalce, nakazujejo, da bi bilo treba $v$ prvem koraku preveriti in izbolišati nadzor nad rezultati s ciljem uveljavitve trdnega kontrolinga. Pri nadaljnjem raziskovanju in iskanju rešitev bo treba upoštevati tudi problematiko partnerstva, pri katerih rezultati raziskave izzvenijo $v$ pasivni drži prepoznavanja problema in nerazumevanja lastne vloge in odgovornosti lokalne skupnosti za razvoi področja.

Obravnava druge hipoteze je ugotovitve o ne-prepoznavanju problema še podkrepila. Nekoliko višja ocena lastnega delovanja od ocene delovanja izvajalcev kaže na to, da občinske uprave zelo verjetno prepoznavajo svoje delovanje kot manj problematično in ključne odgovornosti za kakovostno delovanje nalog pripisujejo izvajalcem.

\section{Zaključek}

$\checkmark$ prispevku smo predstavili problem upravljanja dejavnosti izvajanja nalog lokalne skupnosti. Izhajajoč iz predpostavke, da je celovito obvladovanje kakovosti ključno izhodišče za napredek tega področja, smo s pomočjo uporabe modela CAF razkrili priložnosti za izboljšanje. Kot temelina težava celovitega obvladovanja kakovosti $v$ izvajanju nalog lokalne skupnosti se je izkazala nejasna razporeditev odgovornosti glede izvajanja teh nalog.

Potrdili smo predpostavko, da je treba pri ocenjevanju oziroma samoocenjevanju upoštevati vloge samoocenjevalcev (lokalna skupnost $\leftarrow$ izvajalec naloge) in $\vee$ modelu upoštevati neposredno samoocenjevanje (ocenjevanje lastne dejavnosti) in posredno samoocenjevanje (ocenjevanje dejavnosti drugega). Navzkrižno ocenjevanje omogoča razkrivanje razumevanja odgovornosti in vlog pri akterjih (lokalni skupnosti, izvajalcih nalog), kar omogoča obravnavo posameznega primera $v$ luči modelov dobrih praks.

Zakonski okvir in splošna pravila delovanja lokalnih skupnosti zahtevajo od odgovornih, da vzpostavijo trden upravljavski okvir, podprt z ustreznim celovitim pristopom $k$ celovitem obvladovanju kakovosti.

54 Uprava, letnik IX, 2/2011 
Področje ni dovolj raziskano, teoretična izhodišča so preveč ohlapna, da bi jih lahko brez večjega truda vpeljali v prakso. Problem je zato velik izziv tako za raziskovalce kot za praktike. Razviti je treba teoretičen okvir, pripraviti priporočila dobre prakse, zagotoviti prenos znanja in ponuditi strokovno podporo pri uveljavitvi le teh.

Dr. Jože Benčina je docent na Fakulteti za upravo za področje ekonomike javnega sektoria. Je diplomant matematike, magistriral in doktoriral pa je na Ekonomski fakulteti Univerze v Ljubljani iz informacijsko upravljavskih ved. Več kot deset let je delal kot samostojni inovator na področju informatike in zatem približno enako časa kot vodja Centra za podporo uporabnikom na Centru vlade za informatiko. Na Univerzi v Ljubljani je redno zaposlen od leta 2006. Niegovo raziskovanje obsega metode za merjenje rezultatov delovanja javnega sektoria in metode za optimizacijo odločanja v javnem sektoriu z uporabo mehke logike. Rezultati njegovega raziskovalnega dela so aplikacije modelov, kot je model odločanja za lokalno samoupravo, model uravnoteženih kazalnikov z mehkimi ocenjevalnimi drevesi in model kazalnikov učinkovitosti $v$ zdravstvu. Rezultate svojega dela redno predstavlja na tujih univerzah in objavlja $v$ mednarodnih publikacijah.

Dr. Srečko Devjak je na Fakulteti za upravo redni profesor za področje kvantitativnih analiz za podporo upravljanju. Zaključil je dodiplomski študij matematike, magistrski študij operacijskih raziskav in leta 1987 na Ekonomski fakulteti Univerze $v$ Ljubljani doktoriral iz informacijsko upravljalskih znanosti. V obdobju 1975-1992 je bil zaposlen kot svetovalec za področje razvoja ekonomike in organizacije poslovanja, $v$ vodilnih slovenskih svetovalnih inštitutih. Od leta 1992 je redno zaposlen na Univerzi v Ljubljani. Na Fakulteti za upravo je bil v obdobju 19982005 prodekan za študentske in študijske zadeve in dekan od 2005 do 2009. Raziskuje metode in modele za optimiranje delovanja organizacijskih sistemov. V okviru raziskav je razvil posebne modele in jih apliciral, kot so npr. lesna bilanca Slovenije, proračunski kazalniki občin, kazalniki učinkovitosti investicij $v$ zdravstvu. Rezultate raziskav redno predstavlja $v$ okviru predavani na tujih univerzah in objav $v$ mednarodnih publikacijah. 
Jože Benčina, Srečko Devjak

Celovito obvladovanje kakovosti pri izvajanju nalog lokalne

skupnosti: primer predšolske vzgoje

\section{Literatura in viri}

- Bou-Llusar, J.C. et al. (2009). An empirical assessment of the EFQM Excellence Model: Evaluation as a TQM framework relative to the MBNQA Model. Journal of Operations Management 27(1), 1-22.

- Bugdol, M. \& Jarzebinski, M. (2010). The Possibilities of Applying the Common Assessment Framework Model in Service quality Improvement. Organizacijø Vadyba: Sisteminiai Tyrimai (55), 41-53.

- CAF (2009). Skupni ocenjevalni okvir za organizacije v javnem sektoriu. Pridoblieno 2. 7. 2010, s

http://www.mju.gov.si/si/delovna_podrocja/kakovost_v_javni_upravi/skupni _ocenjevalni_okvir_caf/

- Calvo-Mora, A., Leal, A. \& Roldán, J. L. (2005). Relationships between the EFQM Model Criteria: a study in Spanish Universities. Total Quality Management 16(6), 741-770.

- Castresana, J. I. \& Fernández-Ortiz, R. (2005). Theoretical foundation of the EFQM Model: the resource-based view. Total Quality Management 16(1), 31-55.

- Ghent (2006). TQM with CAF and BSC as sustaining systems. The 4th Quality Conference for Public Administrations in the EU - Building Sustainable Quality. Pridoblieno 30. 5. $2011 \mathrm{~s}$ http://www.4qconference.org/liitetiedostot/bp_long_descriptions/BelgiumA_l ong.pdf

- Kovač, P. (2002). Zakaj in kako uvesti evropski model kakovosti Common Assessment Framework - CAF tudi v slovensko upravo. Ljubljana: Ministrstvo za notranje zadeve, Urad za organizacijo in razvoj uprave.

- Kovač, P. \& Kern-Pipan K. (2005). Celovito izboliševanje javne uprave z integracijo različnih pristopov na temelju modela odlicnosti EFQM. Zbornik povzetkov, konferenca Sodobna javna uprava, Slovenija, Portorož, 23. - 25. 05. 2005.

- Raziskava občine (2010). Zbrani podatki ankete za lokalne skupnosti, predšolska vzgoja. Dostopno na:

https://docs.google.com/fileview? id =0B7wT5WqiJpPSZDQ1MDdhYmY†O WQxZCO0MDRhLWlyMTItYmQ3NiU2NTUxODZl\&hl=en, ali https://docs.google.com/leaf?id=0B7wT5WqiJpPSOGNjOWU4ZjQtMWQ 5NCO0ZTNiLTkyMictM2U5NmM5NDU4NmQw\&hl=en.

- Vlaj, S. (2001). Lokalna samouprava. Ljubljana: Visoka upravna šola. 
Jože Benčina, Srečko Devjak

\section{Celovito obvladovanje kakovosti pri izvajanju nalog lokalne}

skupnosti: primer predšolske vzgoje

\section{Pravne podlage}

- Zakon o lokalni samoupravi. Ur. I. RS, 72/1993, 6/1994, 20/1995, $44 / 1996,26 / 1997,70 / 2000,108 / 2003$ in 60 in 94/2007.

- Zakon o organizaciji in finansiranju vzgoje in izobraževanja (ZOFVI). Ur. I. RS, 12/1996, 16/2007 in 22/2009.

- Zakon o vrtcih. Ur. I. RS, 12/1996, 44/2000, 78/2003, 100/2005, $25 / 2008$. 